\title{
Possíveis dilemas envolvendo a pessoa transexual requalificada e terceiros que podem ter seus registros em parte alterados
}

Possible dilemmas involving the requalified transgender person and third parties who may have their records partly changed

Katylene Collyer Pires de Figueiredo', Gabriel Eduardo Schutz ${ }^{\mathbf{2}}$

DOI: 10.1590/0103-11042019S414

RESUMO A alteração do nome e do registro da pessoa transexual pode afetar a esfera jurídica de terceiros com os quais têm ou tiveram vínculo jurídico. Neste artigo, abordam-se os possíveis conflitos entre a pessoa transexual requalificada e terceiros que poderiam resultar em seus registros alterados, como os descendentes e ex-cônjuges. A partir de uma análise de conflitos hipotéticos, conclui-se que, embora formalmente caiba ao juiz encontrar a solução do conflito a partir de uma hermenêutica adequada, não há uma única solução. Assim, a ponderação dos princípios ocorrerá somente diante da situação concreta sub judice, não podendo o magistrado descurar do fato de que entre suas funções está a proteção dos direitos humanos.

PALAVRAS-CHAVE Pessoas transgênero. Registro civil. Direitos humanos.

ABSTRACT Changing the name and civil registration of the transgender person may affect the legal sphere of third parties with whom they have or had legal ties. This article discusses he possible conflicts that may involve the requalified transgender person and third parties that could result in their altered civil records, such as descendants and former spouses. Based on an analysis of hypothetical hypotheses, it can be concluded that while it is formally up to the judge to find a conflict resolution through an appropriate measure, there is no single solution.

KEYWORDS Transgender person. Civil registration. Human rights.

1 Tribunal de Justiça do Estado do Rio de Janeiro (TJRJ) - Rio de Janeiro (RJ), Brasil.

katylenepires@tirj.jus.br

2 Universidade Federal do Rio de Janeiro (UFRJ), Instituto de Estudos em Saúde Coletiva (lesc) - Rio de Janeiro (RJ), Brasil. 


\section{Introdução}

A alteração dos registros da pessoa transexual, direito consagrado pelo Supremo Tribunal Federal (ADI 4275 e RE 670.422)' , pode, em alguns casos específicos, derivar em conflitos com terceiros no âmbito das relações familiares. Mais especificamente, ex-cônjuges e descendentes podem se opor a ter seus próprios registros em parte alterados como decorrência do direito à alteração registral por parte da pessoa transexual.

A possibilidade de que esse tipo de conflito resulte judicializado demandaria a busca de uma hermenêutica adequada que possibilite ao Poder Judiciário dar as sentenças mais justas para cada caso. No entanto, o confronto entre os direitos de uns e outros aparece, a priori, como dilema, isto é, sem uma única forma de ponderar qual dos princípios em disputa prevalece sobre o outro.

Dessa forma, o objetivo deste ensaio é analisar os possíveis conflitos envolvendo a pessoa transexual requalificada e terceiros que poderiam resultar, contra a sua vontade, com seus próprios registros alterados.

Este estudo é um recorte de uma dissertação de Mestrado Profissional em Direito, Justiça e Saúde, defendida no Programa de Pós-graduação em Saúde Pública, da Escola Nacional de Saúde Pública Sergio Arouca, na Fundação Oswaldo Cruz. Nesse contexto, uma pesquisa em bases de dados judiciais, desenvolvida pelos autores no período 2017-2018, revelou a inexistência, até esse momento, de sentenças prolatadas sobre este tipo de lide no Poder Judiciário brasileiro. Portanto, para atingir o objetivo proposto, optou-se por proceder à análise de três situações hipotéticas potencialmente conflitivas a partir de relações familiares básicas da pessoa transexual: i) casamento; ii) divórcio; e iii) descendência.

Em cada situação, a análise foi desenvolvida considerando os potenciais litígios jurídicos como dilemas de princípios contraditórios que devem ser ponderados por juízes e juízas, problematizando a preponderância dos direitos humanos na hora do julgamento.

\section{Contexto jurídico da alteração de registro de pessoas transexuais}

Em regra, o documento de identificação registral de toda pessoa é a certidão de nascimento, que contém os elementos básicos de sua identificação. Ela é o primeiro documento de validade jurídica de uma pessoa. Ele comprova a sua existência, idade, nacionalidade, o nome dos seus pais, além de outras informações. Sem esse registro, o indivíduo fica impedido de exercer os seus direitos civis, políticos, econômicos e sociais.

Não obstante, após o casamento civil, a pessoa natural passa a utilizar a certidão de casamento para embasar a confecção de todos os demais documentos de identificação, ou seja, para obter carteira de identidade, carteira profissional, de habilitação, passaporte etc.

Ocorre que, mesmo após o divórcio, a certidão de identificação pessoal continua a ser a certidão de casamento, agora com o divórcio averbado, da qual inclusive decorre o novo estado civil, qual seja divorciado. Assim, se a pessoa transexual deseja mudar de nome e de gênero no registro civil, terá, por consequência, que alterar também a certidão de casamento, mesmo que isso ocorra após o divórcio.

Diante disso, pode surgir um questionamento relevante. O provimento do Conselho Nacional de Justiça ${ }^{2}$ dispõe que a alteração só pode ocorrer com anuência do outro cônjuge, o que acarreta que, se não houver concordância, a alteração não poderá ser efetuada de forma administrativa, cabendo à autoridade judicial decidir a questão.

No mesmo sentido, irá se analisar a situação da alteração do prenome no assento de nascimento dos filhos anteriores à readequação civil.

Assim, cabe analisar por separado três situações hipotéticas básicas. 


\section{Potenciais situações de conflito com um terceiro gerada pela requalificação de pessoa transexual}

\section{Pessoa transexual casada}

Na hipótese de a pessoa transexual ser casada e, mesmo após a requalificação, continuar casada, sem conflitos em confronto, bastaria apenas averbar o novo nome e gênero na certidão de casamento original. Nessa hipótese, há a concordância do outro cônjuge como dispõe o Provimento ${ }^{\circ}$ 73 do Conselho Nacional de Justiça.

Antes de o ordenamento brasileiro permitir o casamento de pessoas do mesmo sexo, havia acirrada discussão acerca da possibilidade de a pessoa transexual casada realizar a cirurgia de redesignação sexual, bem como fazer a alteração do prenome e do sexo no registro civil. Atualmente, essa discussão encontra-se ultrapassada na medida em que, após a Emenda Constitucional $n^{0} 66^{3}$, é possível a dissolução do casamento pelo divórcio sem qualquer requisito prévio, assim como não há impedimento para o casamento entre pessoas do mesmo sexo.

A referida conclusão decorre das decisões proferidas pelo Supremo Tribunal Federal ${ }^{4}$, na Ação Direta de Inconstitucionalidade (Adin) $\mathrm{n}^{\circ} 4.277$ e na Arguição de Descumprimento de Preceito Fundamental (ADPF) $n^{0} 132$, que deram interpretação conforme a Constituição Federal ${ }^{3}$ para excluir qualquer significado do art. 1.723, do Código Civil que impeça o reconhecimento da união entre pessoas do mesmo sexo como entidade familiar.

Posteriormente, o Conselho Nacional de Justiça $^{5}$ (Resolução $\mathrm{n}^{0}$ 175) regulamentou o tema no que tange ao procedimento de habilitação de casamento nos cartórios, de modo a não permitir que a habilitação fosse negada em razão da identidade de sexo entre os requerentes.

No julgado acima referido, foram considerados diversos princípios constitucionais de Direitos Humanos, em especial, a própria dignidade da pessoa humana, intimidade e liberdade. Também foi mencionado o direito à felicidade como decorrente dos demais postulados.

Naquele julgado, a Corte Constitucional Brasileira ${ }^{6}$ atuou no seu papel contramajoritário de garantir direitos individuais a despeito das normas constitucionais amplas que buscavam a proteção constitucional da família.

Assim, atualmente, no Brasil, são permitidos o casamento e a união estável entre pessoas do mesmo sexo. Apesar da ausência legislativa, talvez a expressar a vontade da maioria, ainda que formal da população, tal direito foi consagrado pela Corte Suprema e tem sido aplicado de forma plena, sem qualquer impedimento ou obstáculo.

\section{Pessoa transexual divorciada}

Considerando que, uma vez que uma pessoa transexual divorciada decida mudar de nome e de gênero no registro civil, terá que, consequentemente, alterar também a certidão de casamento, mesmo que isso ocorra após o divórcio.

Basicamente, vislumbra-se a defesa no sentido da recusa à alteração com base em dois fundamentos principais: Verdade Real e Liberdade Religiosa.

Ao argumentar acerca da Verdade Real, consigna-se que, na época do casamento, a pessoa não exercia e/ou não expressava sua transexualidade. Apagar a referida informação pode causar transtornos de diversas ordens, inclusive para o ex-cônjuge que terá seu registro em parte alterado.

Não obstante, o Princípio da Verdade Real não é absoluto, uma vez que pode ser mitigado nas hipóteses previstas em lei.

O Princípio da Liberdade Religiosa, previsto no art. $5^{\circ}$, VI, da Constituição Federal6, preconiza que todos podem praticar a religião que melhor lhes aprouver ou não praticar nenhuma. Cabe inicialmente destacar que a liberdade é um conceito vasto e, juridicamente, abarca as liberdades específicas consagradas na Constituição, de modo a conferir maior efetividade a seus conceitos. 
A liberdade religiosa não é simplesmente a liberdade de culto ou a de acreditar em determinada conduta, embora estas sejam partes essenciais da liberdade religiosa. Também não se aplica apenas a pessoas religiosas. $\mathrm{Na}$ sua essência, a liberdade religiosa é o direito humano de pensar, agir e expressar o que se acredita profundamente, de acordo com os ditames da própria consciência moral. $\mathrm{Na}$ realidade, a liberdade religiosa foi sempre compreendida em associação com a 'liberdade de consciência' - a liberdade de desenvolver e manter convicções morais e de agir em conformidade com elas. Desse modo, embora a liberdade religiosa abranja a liberdade da crença religiosa e da devoção, também se estende muito para além destas, incorporando a liberdade de agir-para falar livremente em público, para viver de acordo com próprios princípios morais e defender a própria visão moral para a sociedade ${ }^{7}$.

A partir disso, poderíamos imaginar a situação da pessoa que pratica determinada religião que não aceita a homossexualidade ${ }^{\mathbf{8}}$ ou esta não é aceita por parte de seus membros 9 .

Aqui se fala em homossexualidade, uma vez que, na certidão alterada após a requalificação da pessoa transexual, constará que o ex-cônjuge foi casado com pessoa do mesmo sexo. Isto porque, em um casamento heterossexual, caso haja a mudança de sexo por parte de qualquer um deles, passará a constar o casamento entre duas pessoas do mesmo sexo, talvez esse fato seja incômodo para o cônjuge que professe uma religião que veja a homossexualidade como infringência aos desígnios divinos nos quais a pessoa acredita.

Nessa seara, entra a exigência constitucional da proibição do proselitismo religioso, entendido doutrinariamente como manifestação de dogmatismo ou sectarismo tendente à discriminação social dos credos religiosos não prevalentes culturalmente. Certamente, a Constituição permite a expressão de convicções religiosas, mas não ao ponto de promover a arregimentação manipulatória com o intuito, muitas vezes, de obter poder político ${ }^{10}$.
É necessário um olhar atento para os argumentos de exclusão de minorias sob o fundamento da liberdade religiosa na medida em que essa liberdade encontra limites no direito do outro, em especial, dos mais vulneráveis. Não se pode admitir que, no Brasil, país constitucionalmente laico, a religião expressa e declarada de parte dos parlamentares possa impor, na forma de exclusão e segregação, sua forma de pensar a vida e o direito sob o enfoque religioso fundamentalista.

Destaca-se, assim, que há o direito de a pessoa transexual efetuar a alteração registral, uma vez que a identidade de gênero desta está diretamente ligada ao princípio da dignidade da pessoa humana"1, o qual o inclui como consignado na Carta de Princípios de Yogyakarta12.

Como já visto, a dignidade da pessoa humana engloba o direito à liberdade e à intimidade, decorrendo deste o direito ao exercício da própria sexualidade de modo que melhor lhe aprouver. Tal argumento foi usado nos julgamentos que permitiram o casamento entre casais homoafetivos e também no julgamento acerca da alteração do nome e gênero por parte das pessoas transexuais.

Não obstante, a dignidade da pessoa humana é garantida a todos, e como já mencionado, dela decorre o direito de liberdade de exercer a sexualidade e a identidade de gênero da maneira que melhor lhe agradar. Assim, do mesmo modo que a pessoa transexual tem o direito de alterar seu registro para modificar o nome e o gênero, será que o ex-cônjuge não teria também o direito de mantê-lo original, de modo a preservar a informação no sentido de que, à época do casamento, o fenômeno da transexualidade não havia se manifestado? Como compatibilizar esses dois aspectos da dignidade no caso concreto?

Nesse contexto, também está compreendida a liberdade de pensamento, entendida como o plano íntimo da construção da consciência individual daqueles que, por serem heterossexuais convictos, não desejam, por questões de suas próprias intimidades, que constem que foram casados com pessoa do mesmo sexo ${ }^{10}$. 
Necessária será nesses casos uma ponderação dos princípios Constitucionais envolvidos no caso concreto. A técnica da ponderação é utilizada nos chamados hard cases, em que as regras tradicionais de soluções de conflitos entre normas não se aplicam. Cabe ao julgador analisar a questão e aplicar a solução que menos restrinja os direitos de ambas as partes, a fim de tentar equalizá-los, na medida do possível, sem que nenhum direito seja totalmente excluído.

Nesse passo, o juiz torna-se um importante participante do processo de elaboração do Direito ao lado do legislador, fazendo valorações próprias, atribuindo sentido a cláusulas abertas e realizando escolhas. Como aduz Barroso $^{\mathbf{1 3}}$, a legitimação das decisões se dá com base na teoria da argumentação, voltada à demonstração racional.

Talvez, então, fosse possível que, por determinação judicial, ou de lege ferenda, fossem expedidas duas vias da certidão de casamento com a averbação do divórcio, na qual em uma delas constasse a alteração do gênero da pessoa transexual, e na outra, não. Ou mesmo que constasse a alteração sem o devido sigilo, no caso concreto, de modo a demonstrar que, na época do casamento, a pessoa transexual ainda se apresentava como pertencente ao gênero de nascimento ou biológico, ou mesmo que a pessoa transexual fizesse a alteração somente no registro de nascimento e pudesse, a despeito do casamento e divórcio posterior, continuar a usar a sua respectiva certidão de casamento devidamente alterada, preservando-se assim o sigilo da alteração ocorrida.

Consigna-se, por fim, que a solução encontrada tem que observar os direitos humanos da pessoa transexual, os quais visam proteger as minorias vulneráveis. Assim, por outros motivos, a pessoa transexual jamais pode, no caso concreto, ver-se impedida de exercer seu próprio direito da personalidade de alterar seu prenome e gênero.

\section{Descendentes da pessoa transexual}

No que tange aos descendentes da pessoa transexual, há que se separar algumas situações distintas. A primeira delas diz respeito aos filhos nascidos ou adquiridos após a alteração do registro da pessoa transexual, ou seja, aqueles que nasceram depois da alteração, logo, seus registros não serão modificados. A outra hipótese são os descendentes que já existiam antes da alteração registral da pessoa transexual e após a alteração de gênero, que podem ter seus registros em parte alterados ou não.

Nesse aspecto, cabe trazer à baila a diferença entre 'filhos memória' e 'filhos projeto', centrada na percepção de diferentes temporalidades da parentalidade ${ }^{\mathbf{1 4}}$. Os primeiros seriam a materialização da lembrança de que as mulheres transexuais já foram homens ou vice-versa. Desse modo, as relações com os 'filhos memória' são marcadas pelas tensões da nova construção identitária desses sujeitos, as quais podem acarretar, inclusive, ruptura das relações parentais. Já os 'filhos projeto' estão sujeitos a um investimento diferenciado, porque conjugam o desejo de filhos com a consolidação da identidade de gênero atual.

\section{Descendentes nascidos após a requalificação civil da pessoa transexual}

O direito de ter uma família e filhos abarca todas as pessoas e não pode ser restringido indevidamente por parte do Estado. Assim, uma pessoa transexual pode formar sua família da forma que melhor the aprouver.

Nesse sentido, de acordo com a Dra. Patricia Sanches ${ }^{15}$, a identidade de gênero, advinda do desenvolvimento da própria personalidade está ao abrigo do Direito da Personalidade in persona ipsa, quer dizer, um direito sobre a própria pessoa que se relaciona com terceiras partes como direito potestativo. Desta maneira, não estando sujeito a regras predeterminadas ou limitações, cabe ao Estado e à sociedade, apenas, dar o devido respeito. 
Nesse passo, não existem regras no Brasil que previnam ou proíbam o direito à reprodução para qualquer pessoa, incluindo as pessoas transexuais. Essas podem, se assim desejaram, recorrerem à reprodução assistida para concluir o seu projeto de filiação, tanto um homem transexual pode gerar um filho em seu útero, quanto uma mulher transexual pode utilizar seus espermatozoides para fecundar sua esposa ou qualquer outra forma que a evolução da medicina ou da tecnologia possa permitir.

Do mesmo modo, o Estatuto da Criança e do Adolescente ${ }^{16}$ (ECA) admite a adoção por qualquer pessoa ou casal, independentemente da orientação sexual ou identidade de gênero. No processo de adoção precedido normalmente de um processo de habilitação, serão verificadas a idoneidade do casal pretendente e as condições gerais, mas a questão da identidade de gênero ou mesmo a orientação sexual não pode ser considerada fator impeditivo ${ }^{\mathbf{1 7}}$.

Assim, uma pessoa transexual pode ter filhos recorrendo aos métodos de reprodução assistida, à adoção ou mesmo pela da reprodução humana natural, na hipótese da mulher transexual não operada ter relações com um homem transexual que não passou pela ablação dos órgãos internos, com o intuito de procriação.

Esses filhos, sejam de que origem for, lembrando que a Constituição $0^{3}$ veda qualquer discriminação entre os filhos, terão todos os direitos decorrentes da filiação e serão registrados já com o nome dos seus pais devidamente alterados.

Em relação aos 'filhos projeto', como denominou Elizabeth, não vai haver o conflito no que tange à alteração registral, uma vez que anterior ao nascimento, logo, nenhuma outra alteração será necessária com relação a esses descendentes. Nesse passo, consigna-se que, atualmente, nas certidões de registro civil, consta apenas o campo filiação, não havendo qualquer referência a pai e mãe, de modo que não há que se identificar ou questionar qual dos genitores exercerá que papel social na vida da prole; tais questões serão delimitadas ou não ao longo do relacionamento e da convivência dos pais e dos seus filhos. Recomenda-se que a questão seja tratada com naturalidade e sem mentiras, uma vez que todos os seres humanos têm direito a conhecer a própria história, como já foi estabelecido nos casos de adoção, nos quais, inicialmente, questionava-se a necessidade de informar a criança sobre sua origem biológica; e atualmente é um direito que pode ser juridicamente exercido aos 18 anos, mas deve ser informado logo que a criança tenha maturidade emocional para entender.

\section{Descendentes nascidos antes da requalificação civil da pessoa transexual}

\section{DESCENDENTES PLENAMENTE CAPAZES}

Conforme determina o Provimento $\mathrm{n}^{\mathrm{o}} 73$ do Conselho Nacional de Justiça ${ }^{2}$, a alteração no registro destes dependerá de sua anuência; e, caso não haja a anuência, a questão deverá ser debatida na esfera judicial.

Diferentemente da hipótese do ex-cônjuge, a oposição do descendente não afeta diretamente o direito de alteração do nome e gênero da própria pessoa transexual. Assim, esta pode requerer no cartório de registro civil a alteração de seu nome, de seu gênero e obter uma nova certidão de nascimento com a devida alteração.

No entanto, para averbar seu nome novo na certidão do descendente maior de idade, precisará de sua anuência.

Em sede judicial, em tese, poderia o descendente ser contra a alteração por diversos motivos. Entre eles, a liberdade religiosa, na medida em que, talvez, tivesse dificuldade de aceitação da nova situação de um de seus genitores. Por isso, pode-se questionar se tal atitude é discriminatória ou se está contida no direito à intimidade, de não revelar a todos sua própria história que inclui um pai ou uma mãe transexual? A alteração na certidão de nascimento do descendente teria a consequência 
de alterar todos os demais documentos de identificação, como identidade, carteira de motorista, passaporte, entre outros. Assim, após a alteração, ficaria constando que essa pessoa é filha de dois pais ou de duas mães, conforme o caso. Certo é que a realidade retratada no registro após a requalificação é a que existe no momento atual, porém, durante toda infância, e talvez por longo tempo da vida adulta, tenha convivido com um pai e uma mãe de sexos opostos, e essa nova realidade não seja de fácil aceitação, dependendo da forma de criação e do modo dessa pessoa ver o mundo.

Pode-se afirmar que, psicologicamente, as figuras materna e paterna se construam na infância; e os papéis de gênero sejam definidos na psique do indivíduo nessa fase da vida, ocasionando que a alteração desses papéis na vida adulta seja complicada, demandando, talvez, um trabalho de equipe multidisciplinar.

Nesse ponto específico, como não há mais que se falar em poder familiar, já que esse se extingue com a maioridade, a oposição no que tange à alteração registral por parte do descendente maior de idade não afetaria o direito da personalidade da pessoa transexual, uma vez que esta já fizera sua alteração registral nos próprios documentos sem qualquer impedimento.

Quanto ao fato de, em tese, poder deixar de ser pai de seu próprio filho na vida adulta, apesar de ter sido pai ou mãe durante a infância, é difícil imaginar uma solução jurídica, na medida em que os direitos de personalidade de ambos estariam em aparente conflito. Por um lado, o direito do filho maior e capaz de não ver alterado seu registro de nascimento, e do outro, o direito da pessoa transexual redesignada de fazer constar seu novo nome no documento de seu filho adulto.

Certo é que pessoas adultas, na prática, podem romper os vínculos familiares pelos mais diversos motivos ou desentendimentos, não tendo a lei ou o juiz o poder de impedir o afastamento. Não é por uma eventual ordem judicial que determine a alteração que esses laços não irão se romper.

Desse modo, é difícil admitir a alteração do nome e do gênero no assento civil dos descendentes maiores e capazes das pessoas transexuais. É certo que tal oposição não afetará o direito de a pessoa transexual alterar seu próprio registro e de exercer com plenitude sua própria personalidade, independentemente da aceitação do outro, ao qual cabe apenas o direito/dever de respeito.

Consigna-se, por fim, a situação jurídica do filho que não permitiu a alteração do nome do seu genitor transexual em seus registros. É possível questionar se, em caso de falecimento desse genitor, poderia ele ser herdeiro legítimo.

Juridicamente, provando o descendente que o genitor é a mesma pessoa, o direito de herança está garantido. Todavia, há de se investigar se não terá ocorrido no caso concreto uma das hipóteses de indignidade previstas na lei, já que esse filho não aceitou durante a vida o modo de ser e de buscar a felicidade de seu genitor, mas, após o falecimento, pretende a herança deste.

A indignidade constitui pena civil que priva do direito de herança não só os herdeiros, mas também os legatários que cometeram os atos criminosos ou reprováveis contra o autor da herança, ou seja, a lei, ao conceder o afastamento do herdeiro indigno, faz um juízo de reprovação, tendo em vista a gravidade do ato.

Todavia, apesar de eventual questionamento ético acerca da legitimidade moral do descendente que rejeitou em vida o ascendente transexual, o direito de herança é garantido constitucionalmente e só pode ser suprimido nas hipóteses taxativamente previstas em lei. Assim, provada a ascendência, presente estará o direito hereditário.

\section{DESCENDENTES MENORES}

A alteração no registro dos descendentes menores dependerá, para ser feita em cartório, da anuência do outro genitor. Caso este concorde, a alteração poderá ser realizada na via judicial.

Em caso de oposição, a questão a ser debatida judicialmente envolverá o Princípio do Melhor Interesse da Criança e do 
Adolescente ${ }^{\mathbf{1 8}}$, consagrado na Constituição ${ }^{\mathbf{3}}$ e no próprio $\mathrm{ECA}^{16}$.

A pessoa transexual requalificada não perde o poder familiar em relação aos filhos menores, já que a extinção desse poder/dever só ocorre nas estritas hipóteses previstas na lei. Assim, poderá pleitear os direitos e deveres daí decorrentes, já que a condição de pessoa transexual não lhe retira o poder familiar.

Não obstante, pontua Camila Gonçalves ${ }^{19(270)}$ :

Nessa quadra, em que pese a ausência de efeitos imediatos provocados pela identidade de gênero nas relações entre pais e filhos, a doutrina reconhece a possibilidade de advirem restrições ao poder familiar do transexual, sempre à luz do melhor interesse da criança, na hipótese de ficar demonstrado que o convívio possa prejudicar o desenvolvimento infantil.

Frisa-se, neste ponto, que o poder familiar é o conjunto de deveres e direitos dos pais em relação aos filhos menores.

As atribuições naturais, inerentes a ambos os pais, independentemente da relação conjugal, são as de criar, educar, proteger, cuidar, colocar limites, enfim, dar-lhes o suporte necessário para sua formação moral e psíquica para que adquiram responsabilidade e autonomia (arts. 1630-1633 do Código Civil) ${ }^{20}$.

Em regra, esse poder/dever é exercido por ambos os genitores; e, em caso de conflito, a questão deve ser levada a juízo. Assim, se, por exemplo, um dos genitores conceder autorização para casar antes da maioridade e ou outro genitor negar, o juiz em atenção ao princípio do melhor interesse do menor analisará se concederá ou não, no caso concreto, autorização para casamento suprindo a autorização negada por parte do genitor discordante.

Decorre do poder familiar, também, o direito de convivência entre pais e filhos. Certo é que a não alteração do nome e do gênero do genitor transexual no registro do filho não impede, a priori, o exercício do poder familiar, mas pode dificultar, já que com o próprio registro alterado e o do filho não alterado haverá divergência entre o documento da pessoa transexual e o de seu descendente, de modo que em caso de eventual necessidade de demonstrar a qualidade de genitor, essa seria difícil. Imagina-se a hipótese da pessoa transexual que deseja viajar dentro do País com seu filho. Dispõe o art. 83 do $\mathrm{ECA}^{16}$ que a criança pode viajar dentro do território nacional com qualquer um de seus genitores, assim, teria a pessoa transexual requalificada que demonstrar, no caso concreto, sua qualidade de genitor.

$\mathrm{O}$ antes citado Princípio do Melhor Interesse da Criança e do Adolescente é a base fundamental de toda decisão que envolve criança e adolescente. Este princípio preconiza que, diante do caso concreto, o julgador verifique a situação que, de forma mais completa, proteja os interesses do menor envolvido. Assim, em um processo de guarda, por exemplo, não analisa o julgador se o deferimento da guarda do menor atende aos interesses da mãe ou do pai, mas, sim, do menor. Inclusive, em atendimento ao princípio suprarreferido, é até possível que, em uma situação específica, a guarda seja deferida a um terceiro que revele melhores condições de criar e educar o menor e com ele tenha relações de afinidade e afetividade.

Assim é que a Convenção Internacional sobre os Direitos das Crianças, que adotou a doutrina da proteção integral, reconhecendo direitos fundamentais para proteção da criança e do adolescente, fixou como paradigma o princípio do melhor interesse ${ }^{17}$.

A questão da alteração do nome da pessoa transexual no registro de seus filhos menores dependerá de diversos fatores no caso específico. $\mathrm{O}$ viés de proteção volta-se para o menor e para a análise da situação deste; e, diante da existência de um genitor transexual, cuja relação poderá ser marcada por tensões, o julgador deverá buscar apoio nas equipes multidisciplinares que atuam nas varas de família para embasar sua decisão. A realidade posta não pode ser omitida da criança, mas talvez só os técnicos especializados possam auxiliar no momento que essa verdade for revelada, se for o caso. 
Em decorrência da vulnerabilidade da criança, dependendo da idade e do estágio de desenvolvimento que atravessa, é de suma importância o auxílio profissional de um psicólogo ou de assistente social21.

No âmbito do Tribunal de Justiça do Estado do Rio de Janeiro, os juízes com competência de família têm apoio técnico especializado para auxiliar no deslinde das questões complexas envolvendo as relações familiares. Essas equipes são formadas por psicólogos, assistentes sociais e comissários de infância e juventude, os quais estão em frequente atualização. $\mathrm{O}$ apoio da equipe e a possibilidade de adoção de formas consensuais de resolução de conflito podem ser muito úteis, como, por exemplo, a constelação familiar já aplicada em muitos casos de conflito familiar intenso.

Há de se atentar para o fato de que, em regra, as crianças não têm preconceitos próprios, mas, sim, absorvidos da sociedade e, mais especificamente, dos genitores. Caberá um olhar atento na medida em que o genitor cisgênero detentor da guarda exclusiva possa estar abordando de forma negativa a questão da transexualidade, e, por tal motivo, possa o menor estar rejeitando o outro genitor. Inclusive, esse comportamento pode configurar ato de alienação parental, sujeito as consequências próprias da lei.

Nesse sentido, cabe trazer à colação as palavras de Tereza Rodrigues Vieira22(185,186):

Destaque-se aqui, que o genitor cisgênero não deve reproduzir o preconceito internalizado pela sociedade, pois a diversidade sexual deve ser vista com naturalidade, uma vez que não é considerada doença. Já houve bastante progresso na jurisprudência no tocante ao respeito à diversidade sexual, além disso os pais devem educar seus filhos para a diversidade, respeito ao diferente e inclusão social. Os pais cisgênero devem evitar alienação parental em decorrência da transexualidade do outro cônjuge, assédio moral e ataque a autoestima, pois isto poderá causar danos e efeitos negativos no bem-estar do próprio filho, transformando-o em sujeito transfóbico

e intolerante às minorias sexuais

[...]

É essencial que a veracidade sobre a filiação seja representada na documentação do fiIho, caso contrário sujeitará o genitor ao não exercício do pleno poder familiar ou impedirá o cumprimento de obrigações, com base no hipotético erro de filiação. O convívio com o filho é de suma importância para aquele que adequou sua documentação.

Assim, uma campanha de desmoralização feita pelo genitor cisgênero pode caracterizar ato de alienação parental ${ }^{23}$. Nesses casos, o filho é utilizado como instrumento da agressividade, sendo induzido a odiar o outro genitor. Normalmente, ocorre nos casos em que um dos genitores não consegue elaborar bem o luto da separação, com isso, a criança é levada a se afastar do outro genitor ${ }^{24}$. Assim, deve o julgador ter extrema atenção, uma vez que a alienação parental é muito prejudicial ao menor e sujeita o genitor alienante a diversas sanções legais, que vão desse a advertência até a perda da guarda.

\section{Discussão}

O tema da transexualidade, como quaisquer outras manifestações que destoam da heteronormatividade, desperta muitas dúvidas e questionamentos.

O próprio conceito de pessoa transexual não é uniforme, nem único, isto porque as pessoas transexuais são, em primeiro lugar, seres humanos, os quais manifestam a sua maneira de ser de forma única e livre de qualquer conceito prévio. São cidadãos que se manifestam e se percebem com a identidade de gênero diferente do esperado. Não se pode negar que, em regra, as pessoas com os órgãos genitais de mulher se identificam com o gênero feminino e os indivíduos que nascem com as características de homem se identificam com o gênero masculino. Isto é 
o que ocorre na maioria dos casos, o que caracteriza tais pessoas como cisgênero. Com as pessoas transexuais ocorre o inverso, ou seja, são expressão de uma minoria, que, todavia, não pode ser invisibilizada pela imposição da cultura dominante.

Os direitos dessa parcela da população devem ser protegidos e garantidos, especialmente porque decorrem dos próprios direitos humanos garantidos nos documentos internacionais e na própria Constituição Federal. Para tanto, fez-se necessária, ao longo do tempo, a especificação desses direitos inerentes a todos os seres humanos, os quais nascem gerais e aos poucos vão se detalhando de forma a proteger com maior eficácia e efetividade o direito dos mais vulneráveis.

Demorou um pouco, mas atualmente é indene de dúvidas que esses direitos devem ser objeto de proteção por parte de todas as demais pessoas e, principalmente, por parte do Poder Judiciário.

A fim de regulamentar o procedimento nos Cartórios, a Corregedoria Nacional de Justiça editou a Resolução $\mathrm{n}^{0} 73$, que padronizou o procedimento no País. É válida e necessária a uniformização na regulamentação do assunto, porém tal resolução não é isenta de críticas.

Não obstante, a alteração do nome e do gênero das pessoas transexuais pode interferir, de modo a alterar a esfera jurídica de terceiros com os quais estes se relacionaram antes da alteração.

Nesse aspecto, o princípio da autonomia deve ser visto com especial atenção, na medida em que este preconiza que todos devem ser livres e iguais na determinação de suas próprias vidas, desde que não exerçam esse direito a fim de negar os direitos dos outros.

No âmbito familiar, essas relações podem ser marcadas por tensões, e as demandas de retificação no registro de terceiros certamente serão levadas ao judiciário.

Muitas vezes poderá se verificar diversos direitos em aparente colisão, tais como dignidade da pessoa humana em conflito com a liberdade religiosa ou com o melhor interesse da criança, entre outros.
Todavia, a liberdade religiosa não pode ser exercida de tal forma que uma minoria seja intencionalmente excluída e reprimida. A assertiva acima é notadamente verdadeira em momentos como o atual, quando grupos religiosos se organizam de tal forma simbólica e discursiva, de modo a exercer, além de poder no âmbito religioso, o próprio poder político, para impor ao restante da população que não pratica a sua fé seus ideais e conceitos religiosos.

\section{Considerações finais}

As relações familiares das pessoas transexuais são, antes de tudo, relações entre pessoas, e as tensões porventura existentes devem ser trabalhadas no local próprio.

A pessoa que foi casada e agora um dos ex-cônjuges se apresenta de outro gênero não pode negar esse fato, ele existe. $\mathrm{O}$ direito ao sigilo buscado pelas pessoas transexuais em nome do direito à intimidade deve ser sopesado com a realidade.

Negar fatos não diminui preconceitos, porém, certo é que alguns fatos só têm relevância para as pessoas envolvidas, não sendo possível a publicidade ampla acerca da mudança de gênero.

No que tange aos filhos nascidos antes da alteração, a mudança de gênero de um dos genitores pode ser traumática ou não, a depender dos valores interiorizados pela pessoa ao longo de sua vida e da construção social dos papéis de gênero exercido por cada um dos genitores ao longo da vida dessa pessoa.

O mundo ideal é um local no qual cada um possa ser o que é, e possa exercer seu modo de buscar a felicidade, sem ser questionado por fugir do padrão majoritário.

No dia em que nossas crianças forem criadas para inclusão, tais questionamentos não mais farão sentido; e, talvez, este trabalho pareça um registro histórico, de uma época na qual a aceitação das pessoas como elas desejavam ser era extremamente difícil.

Enfim, o mundo sem preconceitos negativos 
é ainda uma utopia, mas a busca por tal ideal deve tornar a viagem da vida muito mais interessante.

Salienta-se que ser juiz é estar atento a todas essas questões que acompanham a humanidade e decidir sempre com os olhos voltados para a proteção da dignidade humana, valor supremo e insuperável. Em suma, cabe ao juiz, diante do caso concreto, encontrar, a partir de uma hermenêutica adequada, qual a solução do conflito capaz de amenizar a dor, superar o sofrimento e restaurar a paz.

Desse modo, a análise dos processos envolvendo possíveis conflitos de interesses entre a pessoa transexual e terceiros que venham a ter seus registros em parte alterados deverá observar o princípio da dignidade da pessoa humana dos envolvidos, em especial, da parte mais vulnerável. Não há uma única solução, a ponderação dos princípios ocorrerá somente diante da situação concreta sub judice, não podendo o magistrado descurar do fato de que, entre suas funções, está a proteção dos direitos humanos.

\section{Colaboradores}

Figueiredo KCP (0000-0003-1967-2395)* contribuiu substancialmente para a elaboração do rascunho; para a concepção, o planejamento e para a análise dos dados. Schutz GE (00000002-1980-8558)* contribuiu significativamente para a revisão crítica do conteúdo e participou da aprovação da versão final do manuscrito.

\section{Referências}

1. Supremo Tribunal Federal. STF reconhece a transgêneros possibilidade de alteração de registro civil sem mudança de sexo [internet]. Supremo Tribunal Federal. 2018 mar 1. [acesso em 2018 mar 15]. Disponível em: http://www.stf.jus.br/portal/cms/verNoticiaDetalhe.asp?idConteudo=371085.

2. Conselho Nacional de Justiça. Provimento $n^{\circ} 73$, de 28 de junho de 2018 [internet]. Dispõe sobre a averbação da alteração do prenome e do gênero nos assentos de nascimento e casamento de pessoa transgênero no Registro Civil das Pessoas Naturais (RCPN). [acesso em 2019 dez 4]. Disponível em: http://www. recivil.com.br/noticias/noticias/view/provimento-n-73-do-cnj-regulamenta-a-alteracao-de-nome-e-sexo-no-registro-civil.html.

3. Brasil. Emenda Constitucional $\mathrm{n}^{0} 66$, de 13 de julho de 2010 [internet]. Dá nova redação ao $₫ 6^{\circ}$ do art. 226 da Constituição Federal, que dispõe sobre a dissolubilidade do casamento civil pelo divórcio, suprimindo o requisito de prévia separação judicial por mais de 1 (um) ano ou de comprovada separação de fato por mais de 2 (dois) anos. Diário Oficial da União. 14 Jul
${ }^{*}$ Orcid (Open Researcher and Contributor ID). 
2010. [acesso em 2019 fev 19]. Disponível em: http:// www.planalto.gov.br/ccivil_03/Constituicao/Emendas/Emc/emc66.htm.

4. Supremo Tribunal Federal. Supremo reconhece união homoafetiva. Supremo Tribunal Federal. 2011 maio 5. [acesso em 2019 fev 1]. Disponível em: http://www.stf.jus.br/portal/cms/verNoticiaDetalhe.asp?idConteudo=178931.

5. Brasil. Resolução $n^{0} 175$ de 14 de Maio de 2013. Dispõe sobre a habilitação, celebração de casamento civil, ou de conversão de união estável em casamento, entre pessoas de mesmo sexo [internet]. Diário Oficial da União. 15 maio 2013. [acesso em 2019 fev 1]. Disponível em: http://www.cnj.jus.br/atos-normativos?documento $=1754$.

6. Brasil. Constituição da República Federativa do Brasil de 1988 [internet]. Brasília, DF: Presidência da República. [acesso em 2018 set 15]. Disponível em: http:// www.planalto.gov.br/ccivil_03/Constituicao/Constituiçao.htm.

7. Silva JA. Curso de Direito Constitucional positivo. 23. ed. São Paulo: Malheiros Editores; 2004. Revista e Atualizada.

8. A Igreja de Jesus Cristo dos Últimos dias [internet]. Notícias Igreja de Jesus Cristo dos últimos dias. 2012 jan [acesso em 2019 dez 4]. Disponível em: https://www.churchofjesuschrist.org/study/ liahona/2012/01/youth/to-the-point/what-is-the-churchs-position-on-homosexuality-is-it-ok-to-be-friends-with-people-who-have-homosexual-feelings?lang=por.

9. Bresciani E. Em ato contra gays, Silas Malafaia diz que união homoafetiva é crime [internet]. O Estado de São Paulo. 2013 jun 5 [acesso em 2019 fev 19]. Disponível em: https://politica.estadao.com.br/noticias/geral,em-ato-contra-gays-silas-malafaia-diz-que-uniao-homoafetiva-e-crime,1039203.

10. Pires TIT. Liberdade de consciência, liberdade de crença e pluralismo político. Rev. Info. Legislativa [internet]. 2012 [acesso em 2019 fev 21]; 49(195):53-
63. Disponível em: https://www2.senado.leg.br/ bdsf/bitstream/handle/id/496597/000966846. pdf?sequence $=1$.

11. Barroso LR. A Dignidade da Pessoa Humana no Direito Constitucional Contemporâneo: Natureza Jurídica, Conteúdos Mínimos e Critérios de Aplicação (versão provisória para debate) [internet]. [acesso em 2018 mar 15]. Disponível em http://luisrobertobarroso.com.br/wp-content/uploads/2016/06/Dignidade_texto-base_11dez2010.pdf.

12. Corrêa SO, Muntarbhorn V, Organizadores. Princípios de Yogyakarta [internet]. [acesso em $2019 \mathrm{fev}$ 21]. Disponível em: http://www.clam.org.br/uploads/conteudo/principios_de_yogyakarta.pdf.

13. Barroso LR. Temas de Direito Constitucional. Rio de Janeiro: Renovar; 2005. Tomo III

14. Zambrano E. Parentalidades “impensáveis”: Pais/ mães homossexuais, travestis e transexuais. Horizontes Antrop. 2006; 12(26):123-147.

15. Sanches P. Famílias Trans no Brasil: O paradoxo da evolução de Direitos e a epidemia transfóbica. Revista IBDFAM: Família e Sucessões. 2017; 22:159-167.

16. Brasil. Lei no 8.069 , de 13 de julho de 1990. Dispõe sobre o Estatuto da Criança e do Adolescente e dá outras providências [internet]. Diário Oficial da União. 14 Jul 1990 [acesso em 2019 fev 21]. Disponível em: http://www.planalto.gov.br/ccivil_03/leis/18069.htm.

17. Maciel KRFLA, Carneiro RMXG, Amin AR. Curso de direito da criança e do adolescente - aspectos teóricos e práticos. São Paulo: Saraiva; 2014.

18. Pereira TS. O Princípio do Melhor Interesse da Criança: da Teoria à Prática. In: Pereira RC, coordenador. Direito de Família: a família na travessia do milênio. Belo Horizonte: Del Rey; 2000.

19. Gonçalves CJM. Transexualidade e Direitos Humanos - O reconhecimento da identidade de gênero entre os direitos da personalidade. Curitiba: Juruá; 2014. 
20. Brasil. Lei ${ }^{\circ} 10.406$ de 10 de janeiro de 2002 [internet]. Institui o Código Civil. Diário Oficial da União. 11 Jan 2002. [acesso em 2019 fev 1]. Disponível em: http://www.planalto.gov.br/ccivil_03/LEIS/2002/ L10406.htm.

21. Vieira TR. Nome e sexo: Mudanças no registro civil. São Paulo: Atlas; 2012.

22. Vieira TR. Transgêneros: Questões bioéticas e jurídicas ainda polêmicas após o reconhecimento pelo STF do Direito à adequação do nome e gênero. In: Pereira RC. Família e Sucessões. Polêmicas, tendências e inovações. Belo Horizonte: IBDFAM; 2018.
23. Brasil. Lei ${ }^{\circ} 12.318$, de 26 de agosto de 2010 [internet]. Dispõe sobre a alienação parental e altera o art. 236 da Lei no 8.069, de 13 de julho de 1990. Diário Oficial da União. 26 Ago 2010. [acesso em 2019 fev 19]. Disponível em: http://www.planalto.gov.br/ccivil_03/_Ato2007-2010/2010/Lei/L12318.htm.

24. Dias MB. Manual de Direito das Famílias. São Paulo: Editora Revista dos Tribunais; 2013.

Recebido em 23/08/2019

Aprovado em 5/11/2019

Conflito de interesses: inexistente

Suporte financeiro: não houve 